SECTION 21. Pedagogy. Psychology. Innovations in the field of education.

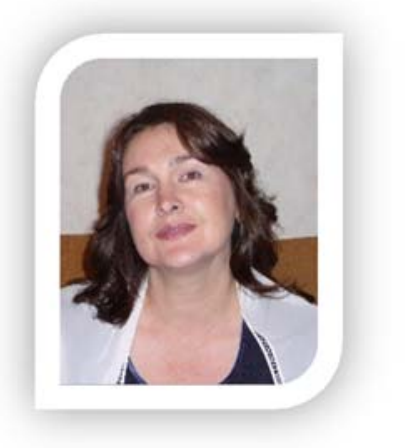

Irina Pavlovna Vasylashko

Head of the department of educational processes monitoring The Institute of innovation techniques and education content of Ministry of Education and Science of Ukraine

Ukraine, Kiev

vip2803@bigmir.net

\title{
DEVELOPMENT OF HEALTH-SAVING COMPETENCE OF "FUNDAMENTALS OF HEALTH" TEACHERS IN POSTGRADUATE PEDAGOGICAL EDUCATION
}

Abstract: The article deals with importance of the development health-competence of secondary school teachers in accordance with modern requirements. Presents the structure of the competence and direction of health-competence of the teacher of the subject "Fundamentals of Health" in the system of postgraduate pedagogical education using new methodological approaches, one of which is - monitoring.

Key words: methodology, education, health, school, monitoring.

Citation: Vasylashko IP (2014) DEVELOPMENT OF HEALTH-SAVING COMPETENCE OF "FUNDAMENTALS OF HEALTH" TEACHERS IN POSTGRADUATE PEDAGOGICAL EDUCATION. ISJ Theoretical \& Applied Science 8 (16): 69-73.

\section{РАЗВИТИЕ ЗДОРОВЬЕСБЕРЕГАЮЩЕЙ КОМПЕТЕНТНОСТИ УЧИТЕЛЕЙ ОСНОВ ЗДОРОВЬЯ В ПОСЛЕДИПЛОМНОМ ПЕДАГОГИЧНОМ ОБРАЗОВАНИИ}

\begin{abstract}
Аннотация: В статье рассматривается актуальность развития здоровьесберегающей компетентности учителя общеобразовательной школь в соответствии с современныли требованиями. Представлень структура данной компетентности и направления развития здоровьесберегающей компетентности учителя предмета «Основы здоровья» в системе последипломного педагогичного образования с использованием новых методических подходов, одним из которых является мониторинг.
\end{abstract}

Ключевые слова: методика, образование, здоровье, икола, мониторинг.

Противоречие между общественно-государственной потребностью в здоровом поколении и образом жизни подавляющего большинства населения страны привело к необходимости ориентации национальной образовательной системы на сохранение и укрепление здоровья, к острой необходимости мотивирования молодежи вести здоровый образ жизни. Именно поэтому эффективной предпосылкой для создания условий развития здоровой личности стало введение в Государственный стандарт начального, базового и полного среднего образования отрасли «Здоровье и физическая культура», реализуемой через образовательные предметы «Физическая культура» и «Основы здоровья» как инвариантной части базовых учебных планов [1]. Позитивные, в целом, изменения в учебных планах среднего образования повлекли за собой обострение проблемы качественной профессиональной подготовки учителей, которые могли бы полноценно реализовывать основные цели и задачи предмета «Основы здоровья».

Анализ данных мониторинговых исследований Министерства образования и науки Украины свидетельствует, что школы укомплектованы учителями необходимой квалификации на 56\% [2]. Опыт коллег стран Восточной Европы и Центральной Азии 
показывает, что только профессионально компетентный учитель, подготовленный за определенной программой с использованием адекватных здоровьесберегающих технологий, будет готов и мотивирован к применению здоровьесберегающих методов во время обучения и воспитания детей, активному созданию благоприятного для здоровья школьного пространства [3]. Эту проблему возможно решить используя систему последипломного педагогического образования с еe традициями, возможностями и перспективами модернизации процесса подготовки учителя с высоким уровнем профессионализма.

Формирование профессиональной компетентности учителя было предметом научных исследований С. Коломийца [4], А. Орлова [5], В. Синенко [6]. Исследователи В. Бабич, П. Джуринский, А. Богданова, С. Страшко, изучали профессиональную подготовку будущих учителей физической культуры к здоровьесберегающей деятельности и преподаванию предмета «Основы здоровья». Вопросами повышения профессиональной компетентности учителей основ безопасности жизнедеятельности, основ здоровья занимались А. Ващенко, Е. Чернышова, Т. Воронцова, С. Жульова, А. Радченко, Е. Шиян, И. Зенченков и другие. Е. Шатрова разработала теоретическую модель формирования здоровьесберегающей компетентности (ЗСК) педагога [7]. Аспектам формирования ЗСК учителей основ здоровья посвящены публикации Т. Бойченко [8], В. Успенской [9]. Следует, однако, отметить, что проблеме профессиональной подготовки учителей основ здоровья в системе последипломного педагогического образования до настоящего времени уделено недостаточно внимания, особенно вопросам формирования ЗСК. Тем более, что эта компетентность входит в состав комплекса ключевых компетентностей для детей школьного возраста. В связи с тем, что среди ключевых компетентностей педагогов ЗСК нет, развитие её (как ключевой и предметной) в учителей основ здоровья приобретает особое значение.

Включение ЗСК в перечень ключевых для каждого специалиста, работающего сфере образования, позволит решать проблемы, связанные со здоровым образом жизни участников учебно-воспитательного процесса, на качественно новом уровне. Т. Бойченко считает, что основанием включения в перечень ключевых компетентностей ЗСК является значимость здоровья как общечеловеческой ценности, жизненного ресурса, философской категории, которые раскрываются при анализе сущности здоровья с использованием различных подходов - феноменологического, онтологического, гносеологического, холистического, детерминистского, герменевтического. Эта компетентность имеет все признаки ключевой, концентрирует в себе все характеристики социальной, поликультурной, коммуникативной компетенций, направлена на саморазвитие и самообразование, продуктивную и творческую деятельность [8]. Соответственно стандарты и учебные планы, программы последипломного образования учителей основ здоровья должны включать разделы, модули здоровьесберегающего характера, новые формы и методы для разных категорий слушателей с целью эффективного формирования и развития их ЗСК.

На основе проведенного анализа специальных, научных, научно-публицистических источников, требований к профессиональной подготовке, мастерству, умениям и навыкам, личным качествам учителей основ здоровья, изучения их практического опыта работы, понятие ЗСК учителя основ здоровья, на наш взгляд, может быть сформулировано так. Здоровьесберегающая компетентность - интегративное качество учителя, которое имеет сложную системную организацию и выступает как совокупность взаимодействующих и взаимозависимых компонентов ценностно-мотивационного, когнитивного и операционнодеятельного характера. ЗСК как системное образование характеризует личность учителя, уровень сформированности которой проявляется в способности и готовности к здоровьесберегающей творческой педагогической деятельности на основе знаний, умений, навыков и опыта работы в образовательной среде с использованием современных 
технологий для достижения высоких результатов.

На основе анализа научных разработок отечественных и зарубежных исследователей, собственного педагогического опыта нами разработана структура ЗСК, которая достигается путем приобретения соответствующих компетенций (рис. 1).

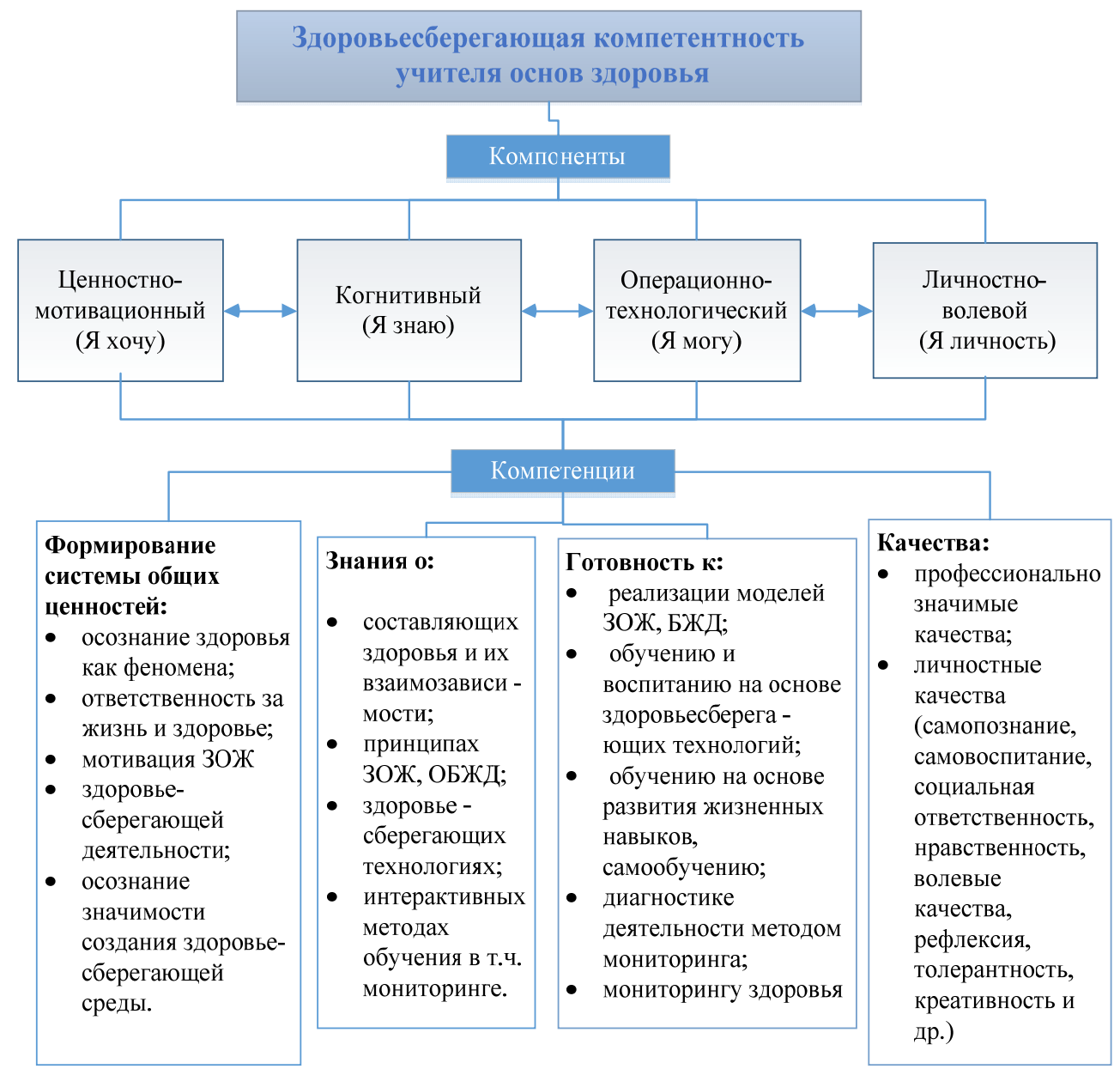

Рисунок 1 - Структура здоровьесберегающей компетентности учителя основ здоровья.

В представленной структуре существует взаимосвязь между отношением учителя к своему здоровью, соблюдением принципов здорового образа жизни (ЗОЖ), уровнем знаний по разным аспектам здоровья и оказанием соответствующего воспитательного воздействия на учеников во время обучения. Если учитель основ здоровья недостаточно осведомлен в вопросах укрепления и восстановления здоровья, имеет низкую мотивацию к ведению ЗОЖ, не толерантен, он, как правило, не имеет и достаточного авторитета среди воспитанников. Ему сложно влиять на формирование мировоззрения учеников, их поведение.

В структуру включено использование здоровьесберегающих педагогических технологий. Учитывая современные потребности и требования к деятельности учителя основ здоровья, в системе последипломного педагогического образования Украины происходит обновление подходов к организации проведения курсов повышения квалификации, создаются условия для самореализации, самообразования педагога. Интерактивные методы обучения используются в различных индивидуализованных комбинациях на семинарах, спецкурсах и особенно в тренингах в соответствии с программами. Это позволяет слушателям курсов не только ознакомиться с теоретической сущностью инновационных методик обучения, но и практически овладеть составляющими здоровьесберегающих технологий, разработать свою собственную вариацию такой 
технологии с учетом особенностей учащихся и их родителей, обсудить его детали со своими коллегами, защитить его основные положения как выпускную работу. Приобретённый во время последипломной подготовки опыт способствует применению уже апробированных технологий.

Среди многих педагогических методов, использование которых характеризует профессиональную компетентность учителя основ здоровья особенное место, на наш взгляд, занимает мониторинг. Учитель основ здоровья может использовать мониторинг как:

1) вектор профессионального развития в процессе формирования ЗСК на всех этапах своей подготовки;

2) инструмент управления процессом своей профессиональной деятельности, развития своего творческого потенциала (самооценка, контроль, диагностика, прогнозирование и т.д.);

3) метод управления качеством образования учеников (качество знаний, уровень формирования умений, навыков ЗОЖ, изменения в БЖД и отношении к здоровью и т.п.);

4) инструмент контроля необходимого уровня здоровьесберегающего образовательного пространства для всех участников учебно-воспитательного процесса;

5) как метод диагностики и коррекции уровня здоровья учащихся.

Все пять аспектов использования мониторинга, на наш взгляд, важны и недостаточно, а то и вовсе не разработаны [10].

Проведение педагогического мониторинга за состоянием здоровья, с целью выявления проблем учебно-воспитательного процесса, для повышения профессионализма педагогов предполагает соблюдение принципов комплексности, системности, междисциплинарности. Процедура его проведения требует сложного взаимодействия квалифицированных специалистов и определенных материально-технических ресурсов. Но эти затраты оправданы благополучием и здоровьем подрастающего поколения.

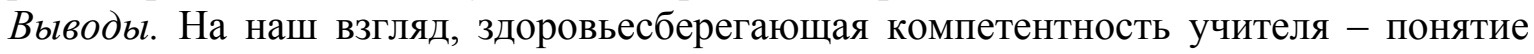
динамическое, полиаспектное и многогранное, её содержание корректируется в соответствии с экономико-политическими изменениями, происходящими в обществе, и процессами модернизации в сфере образования. Структура ЗСК учителя основ здоровья, процесс её развития в системе последипломного педагогичного образования видоизменяются, корректируются в связи с развитием практики ЗОЖ, БЖД. Определение содержания, структуры, методик развития ЗСК учителя основ здоровья требуют дальнейшей разработки, анализа, систематизации и обобщения. Мониторинг в формировании ЗСК учителя имеет сложную структуру, разнообразные функции и требует дальнейшего разностороннего изучения, в первую очередь как метод обучения педагога на этапе последипломного образования.

Дальнейшее исследование целесообразно сосредоточить, в частности, на разработке факторно-критериальной модели оценивания уровня формирования ЗСК учителя.

\section{References:}

1. (2004) Postanova Kabinetu Ministriv Ukraïni vid 14 sichnya 2004. No 24 «Pro zatverdzhennya Derzhavnogo standartu bazovoï i povnoï zagal'noï seredn'oï osviti» Oficiyniy visnik Ukraïni, No 2, pp. 49.

2. Vasilashko IP (2009) Noviy predmet «Osnovi zdorov’ya». Efektivnist' uprovadzhennya (Za rezul'tatami monitoringovogo doslidzhennya 2008 roku) Zdorov'ya ta fizichna kul'tura, No 28 (160), pp. 3-10.

3. YUNESKO (2013) Profilakticheskoe obrazovanie $v$ stranah Vostochnoy Evropy i Central'noy Azii. Obzor normativnoy bazy i suschestvuyuschey praktiki. Itogovyy otchet. 2013, Moscow, OOO «Verdi», pp. 108. 
4. SM Kolomiec, EA Boyarskiy (2007) Obobschennye kompetencii vypusknikov vuzov. Vysshee obrazovanie segodnya No 6, pp. 84-86.

5. Orlova AA (2014) Proektirovanie i organizaciya samostoyatel'noy raboty studentov v kontekste kompetentnostnogo podhoda: Mezhvuzovskiy sbornik nauchnyh trudov. Vypusk 3 Moscow, Direkt, Media, pp. 111.

6. Sinenko VY (1999) Professionalizm uchitelya. Pedagogika No 5, pp. 45-51.

7. Shatrova EA (2012) Teoreticheskaya model' formirovaniya zdorov'esberegayuschey kompetentnosti pedagoga. Vestnik TGPU No2, pp.111-116.

8. Boychenko TE (2013) Pidvischennya rivnya zdorov'yazberezhuval'noï kompetentnosti yak chinnik rozvitku tvorchogo potencialu kerivnih kadriv osviti. Zbirnik naukovih prac. Nac. ped. un-t im. M.P. Dragomanova, izd-vo NPU im. M.P. Dragomanova, Vip. 28, pp. 84-89.

9. VM Uspens'ka (2011) Zdorov'yazberezhuval'na kompetentnist' uchitelya zdorov'ya ta shlyahi iii rozvitku. Visnik pislyadiplomnoï osviti: zb. nauk. prac. UMO NAPN, K.: Vid-vo UMO NAPN, Vip. 2 (15), pp.140-149.

10. O Lokshina, T Lukina, O Lyashenko, O Savchenko (2004) Monitoring yakosti osviti: svitoviy dosvid ta ukraïns'ki perspektivi: Posibnik, Pid zag. red.. O.I. Lokshinoyu, K.: «K.I.S.», pp. 128. 